\title{
A Review on Grid-connected Converter Control for Short Circuit Power Provision under Grid Unbalanced Faults
}

\author{
Jia, Jundi; Yang, Guangya; Nielsen, Arne Hejde
}

Published in:

IEEE Transactions on Power Delivery

Link to article, DOI:

10.1109/TPWRD.2017.2682164

Publication date:

2017

Document Version

Peer reviewed version

Link back to DTU Orbit

Citation $(A P A)$ :

Jia, J., Yang, G., \& Nielsen, A. H. (2017). A Review on Grid-connected Converter Control for Short Circuit Power Provision under Grid Unbalanced Faults. IEEE Transactions on Power Delivery, 33(2), 649 - 661.

https://doi.org/10.1109/TPWRD.2017.2682164

\section{General rights}

Copyright and moral rights for the publications made accessible in the public portal are retained by the authors and/or other copyright owners and it is a condition of accessing publications that users recognise and abide by the legal requirements associated with these rights.

- Users may download and print one copy of any publication from the public portal for the purpose of private study or research.

- You may not further distribute the material or use it for any profit-making activity or commercial gain

- You may freely distribute the URL identifying the publication in the public portal 


\title{
A Review on Grid-connected Converter Control for Short Circuit Power Provision under Grid Unbalanced Faults
}

\author{
Jundi Jia, Student Member, IEEE, Guangya Yang, Senior Member, IEEE, \\ and Arne Hejde Nielsen, Senior Member, IEEE
}

\begin{abstract}
As an increasing amount of converter-based generation on power electronics is connected to power systems, transmission system operators (TSOs) are revising the grid connection requirements to streamline the connectivity of the devices to maintain security of supply. Converter-based generation can behave significantly different from the traditional alternators under grid faults. In order to evaluate the potential impact of future converter-based power systems on protective relays, it is necessary to consider diverse current control strategies of voltage source converters (VSC) under unbalanced faults as the performance of converters primarily depends on their control objectives. In this paper, current control strategies of VSC under unbalanced faults for short circuit power provision are reviewed in two groups, namely power-characteristic-oriented and voltage-support-oriented control strategy respectively. As the fault current provided by converters should be restricted within secure operation limits considering semiconductor capabilities, converter current limit issue is also discussed.
\end{abstract}

Index Terms-Converter control; fault ride through; reactive power; short circuit current; unbalanced faults.

\section{INTRODUCTION}

$\mathbf{I}$ $\mathrm{N}$ the past decade, increasing attention has been paid to the integration of renewable energy into power systems as a concern of the world-wide climate change. It is reported that roughly two-thirds of all anthropogenic greenhouse-gas emission is oriented from energy sector due to the use of fossil fuels [1]. According to Danish Energy Agency, the share of renewable energy will be increased to $33 \%$ by 2020 and the long-term goal is to achieve $100 \%$ renewable energy supply by 2050 , thus eliminating the red dependency on fossil fuels [2].

Conventional fossil-fuel-based power plants have large synchronous generators, which are capable of supplying a number of ancillary services to support power system operation. In contrast, renewable-energy-based generation as well as HVDC transmission is typically interfaced with the grid via power electronic converters. To guarantee a smooth transition of the energy system from conventional synchronous-generatorbased one to future converter-based one, several projects are

Manuscript received November 6, 2016; revised February 1, 2017; accepted March 3, 2017. This work is supported by Danish ForskEL project "Synchronous Condensers Application in Low Inertia Systems (SCAPP)", grant no. 12196, administrated by Energinet.dk.

J. Jia, G. Yang and A. H. Nielsen are with the Center for Electric Power and Energy, Department of Electrical Engineering, Technical University of Denmark, Konges Lyngby, DK-2800, Denmark (e-mail: \{junjia, gyy, ahn\}@elektro.dtu.dk). conducted world-widely to deal with related technical challenges. For example, "MIGRATE" project under the framework of European Union's Horizon 2020 focuses on safeguarding grid stability, changes to control functions, and possible adjustments to grid connection requirements [3]. In Norway, the project "ProSmart" targets to improve classical power system relaying by taking advantages of communication technology [4]. The Danish project "Synchronous Condensers Application in Low Inertia Systems" proposes to equip synchronous condensers to enhance system frequency stability and improve short circuit power level for future low inertia power systems [5]. This project aims to quantify the impact of converter-based power systems on system frequency and voltage characteristics during transients. Protective relay performance and the control system of synchronous condensers will be evaluated through hardware-in-the-loop tests, based on which the optimal design and parameter settings can be determined to provide essential grid services for future converter-based power systems in order to improve system security.

Under grid faults, conventional synchronous generators are able to provide a large amount of fault current, the decaying characteristics of which can be classified into sub-transient, transient and steady-state stages. This current is of great importance to support grid voltage and activate protective relays. In contrast, converters can only provide 1-2 pu fault current depending on their semiconductor capabilities. Nowadays, voltage source converters are gaining popularity in various applications such as wind power plants, photovoltaic power plants, battery storage and HVDC. However, the control systems of VSC are sensitive to grid voltage dips in nature and thus increasing requirements on VSC have been imposed by TSOs such as fault-ride-through (FRT) and voltage support capabilities [6]. During grid unbalanced faults, VSC can exhibit undesirable performance such as output current distortions, DC link voltage oscillations and output power oscillations. Therefore, a variety of control strategies have been proposed to improve the performance of VSC, which enable diverse characteristics of fault current and support grid voltage in different ways. As a result, the characteristics of short circuit power under grid unbalanced faults may be significantly affected in converter-based power systems, which in turn will affect the reliability of protection systems relying on voltage and current signals.

To investigate the potential impact of grid-connected converters on the protection systems, it is necessary to review 
current control strategies of VSC considering grid codes. In [7]-[10], the impact of grid-connected photovoltaics, Type-IV wind turbines and VSC-HVDC on transmission side protection has been investigated. All these studies are based on grid balanced faults and the conventional control method used in these studies is not suitable to evaluate unbalanced scenarios. On the other hand, comprehensive reviews regarding control techniques of VSC have been provided by [11]-[14]. The purpose of [11] is to review the current control techniques of VSC under steady state, without mentioning their performance subject to grid disturbances. Both of [12] and [13] present gridconnected VSC control structures implemented in different reference frames. The design of current controllers is a main concern in [12] while control strategies during unbalanced faults are not discussed. Even though four different control strategies subject to grid faults are introduced in [13], it lacks details of their implementation and grid codes are not taken into account. A more recent work [14] presents a wide range of control strategies under unbalanced grid faults but reactive power control is not comprehensively included. In addition, none of the above works has mentioned techniques regarding the setting of converter current limit. The concept of synchronverter is introduced in [15], where the grid-connected VSC is controlled in a manner that resembles traditional synchronous generators, enabling converter the capabilities of load sharing and voltage regulation. Its application to HVDC transmission and wind farms has been reported in [16] and [17] respectively. This paper aims to review current control strategies of gridconnected VSC under unbalanced grid faults considering grid requirements and converter current limit, for the sake of studying the potential impact of future converter-based power systems on the transmission-side protective relays. In this paper, current control strategies of VSC under unbalanced faults are classified into two groups based on the property that is being controlled directly. This is mainly reflected by how current references are generated. The first group is named "power-characteristic-oriented control strategy" as it focuses on directly controlling oscillations in the output power. Since the second group aims to control the relative amount of positive- and negative-sequence power, which directly impact positive- and negative-sequence voltage at point of common coupling (PCC), it is named "voltage-support-oriented control strategy".

This paper is organized as follows. A short overview on grid requirements is given in Section II. Power-characteristicoriented and voltage-support-oriented control strategies are reviewed in Section III and IV respectively. In Section V, converter current limit issues during grid unbalanced faults are discussed. Case studies with different control strategies are presented and discussed in Section VI. Finally, Section VII presents the conclusions.

\section{GRID REQUIREMENTS}

As an increasing amount of renewable energy being connected to power systems through power converters, TSOs have issued restrictive grid requirements on converter-based generation in form of grid codes. This requires converter-based generation not only to tolerate grid disturbances but also to provide ancillary services as conventional generation does.

\section{A. Fault-ride-through Capability}

Under grid fault conditions, converter-based generation experiences voltage dips at the point of common coupling that can potentially isolate power converters from the faulty area. However, unnecessary disconnections of power generation subject to grid disturbances impose threats to the security of supply of power systems. Therefore, different national and international codes have defined low-voltage fault-ride-though requirements in form of lower limit of a voltage-against-time profile at the PCC [18], [19], whose parameters of voltage and time vary from country to country [20]-[22]. On the other hand, over-voltage problem can occur in non-faulty phases during grid unbalanced faults, which may also lead to power generation disconnection undesirably [23]. As a result, highvoltage fault-ride-through requirements have been imposed in countries such as Australia, Denmark, Spain and Italy. All of these indicate that the control systems of grid-connected converters should be able to safely guard stable converter operation under grid faults.

\section{B. Grid Voltage Support}

Conventional power generation is able to provide fast reactive current injection under grid faults, which is important not only for grid voltage support but also for activation of protective relays. Therefore, reactive current injection from wind farms is required by TSOs internationally, which is summarized in Table I for several European countries based on [19], [22], [24], [25]. For example, Germany enforces additional reactive current injection in terms of positive-sequence amounting to at least $2 \%$ of the rated current for each percent of voltage dip, which should reach $90 \%$ of steady-state value within $50 \mathrm{~ms}$.

TABLE I

REACTIVE CURRENT INJECTION REQUIREMENTS IN EUROPE

\begin{tabular}{l|l|l|l|l}
\hline \hline Country & $\begin{array}{l}\text { Current } \\
\text { Type }\end{array}$ & Character & $\begin{array}{l}\text { Rising } \\
\text { Time (ms) }\end{array}$ & Amount \\
\hline Denmark & - & - & 100 & $\begin{array}{l}\geq 2 \% \text { injection for 1\% PCC voltage } \\
\text { reduction }\end{array}$ \\
\hline Germany & Pos.seq & Additional & $50(90 \%)$ & $\begin{array}{l}\geq 2 \% \text { injection for 1\% PCC voltage } \\
\text { reduction }\end{array}$ \\
\hline Ireland & - & - & $100(90 \%)$ & $\begin{array}{l}\text { At least proportional to the voltage } \\
\text { dip }\end{array}$ \\
\hline Spain & Pos.seq & Absolute & 150 & $\begin{array}{l}3 \%, 0.75 \% \text { or } 0.5 \% \text { injection for 1\% } \\
\text { PCC voltage reduction (depending } \\
\text { on voltage-dip level) }\end{array}$ \\
\hline UK & - & - & - & $\begin{array}{l}\text { Maximum reactive current without } \\
\text { exceeding the transient rating limits }\end{array}$ \\
\hline \hline
\end{tabular}

As can be observed from Table I, specific requirements for unbalanced grid faults are lacking as negative-sequenece current could be injected by converters under grid unbalanced faults. Furthermore, there are still uncertainties in the present grid codes such as how reactive current should be calculated, how rising time is defined. According to [26], system operators may specify a requirement for unbalanced fault current injection from HVDC in the case of unbalanced faults in the future. This can lead to the next generation of grid codes. As 
the "right" behaviour of converter-based generation under grid unbalanced faults is still under open discussion, it is necessary to make a comprehensive review of control strategies for short circuit power provision.

\section{Power-Characteristic-ORIEnted Control STRATEGY}

Typically for a current-controlled VSC system, the control system consists of a slower outer controller and a faster inner current controller. The outer controller regulates DC side voltage, AC side voltage and the output power at the PCC depending on the application and generates current references for the inner current controller that regulates converter current. During grid unbalanced faults, the strategy to generate current references is a crucial aspect that determines the performance of the converter. In this section, control strategies achieving a variety of power characteristics under unbalanced faults are reviewed based on instantaneous power theory [27].

\section{A. Instantaneous Power Theory}

According to instantaneous power theory, the instantaneous active and reactive output power of a three-phase, three-wire voltage source converter can be expressed by:

$$
\begin{aligned}
& p=\mathbf{v} \cdot \mathbf{i} \\
& q=\mathbf{v}_{\perp} \cdot \mathbf{i}
\end{aligned}
$$

where $\mathbf{v}=\left[\begin{array}{lll}v_{a} & v_{b} & v_{c}\end{array}\right]^{T}$ and $\mathbf{i}=\left[\begin{array}{lll}i_{a} & i_{b} & i_{c}\end{array}\right]^{T}$ are voltage vector and current vector at the PCC respectively. The operator "." represents the dot product of vectors and the subscript " $\perp$ " denotes an orthogonal version of the original vector. By applying symmetrical component theory, the voltage and current vector can be represented by:

$$
\begin{aligned}
\mathbf{v} & =\mathbf{v}^{+}+\mathbf{v}^{-}+\mathbf{v}^{0} \\
\mathbf{i} & =\mathbf{i}^{+}+\mathbf{i}^{-}+\mathbf{i}^{0}
\end{aligned}
$$

where superscripts "+", “-” and "0" refer to positive-, negative- and zero-sequence components. With (3) and (4) substituted into (1) and (2), the instantaneous power at the PCC can be rewritten as:

$$
\begin{aligned}
& p=\underbrace{\mathbf{v}^{+} \cdot \mathbf{i}^{+}+\mathbf{v}^{-} \cdot \mathbf{i}^{-}}_{\bar{P}}+\underbrace{\mathbf{v}^{+} \cdot \mathbf{i}^{-}+\mathbf{v}^{-} \cdot \mathbf{i}^{+}}_{\widetilde{P}} \\
& q=\underbrace{\mathbf{v}_{\perp}^{+} \cdot \mathbf{i}^{+}+\mathbf{v}_{\perp}^{-} \cdot \mathbf{i}^{-}}_{\bar{Q}}+\underbrace{\mathbf{v}_{\perp}^{+} \cdot \mathbf{i}^{-}+\mathbf{v}_{\perp}^{-} \cdot \mathbf{i}^{+}}_{\widetilde{Q}}
\end{aligned}
$$

where the constant terms $\bar{P}$ and $\bar{Q}$ result from the interaction between voltage and current in the same sequence while the interaction between voltage and current in different sequences leads to oscillating terms $\widetilde{P}$ and $\widetilde{Q}$. The zero-sequence component is ignored here as it doesn't exist for a three-phase, three-wire system. It can be noticed that any current vector aligned with $\mathbf{v}$ contributes to active power while current vector aligned with $\mathbf{v}_{\perp}$ gives rise to reactive power. In general, the instantaneous power expressed by (5) and (6) is valid in any stationary or rotational reference frames [28], [29].

\section{B. Balanced Current Control}

The objective of this strategy is to inject a set of balanced sinusoidal fault current into the grid during unbalanced faults [30]-[34]. In general, current reference can be represented by:

$$
\mathbf{i}^{r e f}=\mathbf{i}_{P}^{r e f}+\mathbf{i}_{Q}^{r e f}
$$

where $\mathbf{i}_{P}^{\text {ref }}$ and $\mathbf{i}_{Q}^{\text {ref }}$ are current vectors generating active and reactive power respectively, which can be transformed into any reference frame. Then, balanced current control strategy can be realized by setting:

$$
\begin{aligned}
& \mathbf{i}_{P}^{r e f}=\mathbf{i}_{P}^{+, \text {ref }}=\frac{P^{r e f}}{\left|\mathbf{v}^{+}\right|^{2}} \mathbf{v}^{+} \\
& \mathbf{i}_{Q}^{\text {ref }}=\mathbf{i}_{Q}^{+, \text {ref }}=\frac{Q^{\text {ref }}}{\left|\mathbf{v}^{+}\right|^{2}} \mathbf{v}_{\perp}^{+}
\end{aligned}
$$

where $P^{r e f}$ and $Q^{r e f}$ are active and reactive power reference either generated by an outer controller or directly selected. Therefore, the instantaneous output power of a converter under unbalanced faults is simplified as:

$$
\begin{aligned}
& p=\underbrace{\mathbf{v}^{+} \cdot \mathbf{i}_{P}^{+, r e f}}_{\bar{P}}+\underbrace{\mathbf{v}^{-} \cdot \mathbf{i}_{P}^{+, r e f}}_{\widetilde{P}} \\
& q=\underbrace{\mathbf{v}_{\perp}^{+} \cdot \mathbf{i}_{Q}^{+, r e f}}_{\bar{Q}}+\underbrace{\mathbf{v}_{\perp}^{-} \cdot \mathbf{i}_{Q}^{+, r e f}}_{\widetilde{Q}}
\end{aligned}
$$

This indicates oscillating terms exist in both output active and reactive power. It can also be proven that the amplitudes of oscillations in active and reactive power are the same.

\section{Constant Active Power Control}

This control strategy aims to nulify oscillating terms in output active power. According to [29], [33], [35], it can be accomplished by giving current references as:

$$
\begin{aligned}
& \mathbf{i}_{P}^{\text {ref }}=\frac{P^{\text {ref }}}{\left|\mathbf{v}^{+}\right|^{2}-\left|\mathbf{v}^{-}\right|^{2}}\left(\mathbf{v}^{+}-\mathbf{v}^{-}\right) \\
& \mathbf{i}_{Q}^{r e f}=\frac{Q^{r e f}}{\left|\mathbf{v}^{+}\right|^{2}-\left|\mathbf{v}^{-}\right|^{2}}\left(\mathbf{v}_{\perp}^{+}-\mathbf{v}_{\perp}^{-}\right)
\end{aligned}
$$

Then the instantaneous power becomes:

$$
\begin{aligned}
& p=\underbrace{\mathbf{v}^{+} \cdot \mathbf{i}_{P}^{+, r e f}+\mathbf{v}^{-} \cdot \mathbf{i}_{P}^{-,}, r e f}_{\bar{P}}+\underbrace{\mathbf{v}^{+} \cdot \mathbf{i}_{Q}^{-, r e f}+\mathbf{v}^{-} \cdot \mathbf{i}_{Q}^{+, r e f}}_{\widetilde{P}} \\
& q=\underbrace{\mathbf{v}_{\perp}^{+} \cdot \mathbf{i}_{Q}^{+, r e f}+\mathbf{v}_{\perp}^{-} \cdot \mathbf{i}_{Q}^{-, r e f}}_{\widetilde{Q}}+\underbrace{\mathbf{v}_{\perp}^{+} \cdot \mathbf{i}_{P}^{-, r e f}+\mathbf{v}_{\perp}^{-} \cdot \mathbf{i}_{P}^{+, r e f}}_{\widetilde{Q}}
\end{aligned}
$$

Given (14), the only way to eliminate oscillating term $\widetilde{P}$ is to let $Q^{r e f}$ be zero since any existing value in $\mathbf{i}_{Q}^{r e f}$ contributes to oscillations in active power. By further setting $Q^{r e f}$ to zero, (14) and (15) are simplified as:

$$
\begin{aligned}
p & =\underbrace{\mathbf{v}^{+} \cdot \mathbf{i}_{P}^{+, r e f}+\mathbf{v}^{-} \cdot \mathbf{i}_{P}^{-, r e f}}_{\bar{P}} \\
q & =\underbrace{\mathbf{v}_{\perp}^{+} \cdot \mathbf{i}_{P}^{-, r e f}+\mathbf{v}_{\perp}^{-} \cdot \mathbf{i}_{P}^{+, r e f}}_{\widetilde{Q}}
\end{aligned}
$$


resulting in a constant active power and oscillating reactive power with its average value being zero. However, this way of calculating current references cannot inject a certain amount of reactive power. In order to achieve oscillation-free active power and non-zero-average-value reactive power simultaneously, reactive current reference (13) is modified as [33], [36][40]:

$$
\mathbf{i}_{Q}^{r e f}=\frac{Q^{r e f}}{\left|\mathbf{v}^{+}\right|^{2}+\left|\mathbf{v}^{-}\right|^{2}}\left(\mathbf{v}_{\perp}^{+}+\mathbf{v}_{\perp}^{-}\right)
$$

With current references (12) and (18), the instantaneous active and reactive output power can be finally represented by (16) and (15) respectively. It is worth noticing that a set of unbalanced current is injected to the grid and oscillations in double fundamental frequency are registered in reactive power.

\section{Constant Reactive Power Control}

Similar to constant active power strategy, constant reactive power strategy [41], [42] is obtained by applying current references (12) and (13) with $P^{r e f}$ being zero, as any existing value in $\mathbf{i}_{P}^{r e f}$ contributes to oscillating reactive power according to (15). Then the instantaneous power can simplified be as:

$$
\begin{aligned}
p & =\underbrace{\mathbf{v}^{+} \cdot \mathbf{i}_{Q}^{-, r e f}+\mathbf{v}^{-} \cdot \mathbf{i}_{Q}^{+, r e f}}_{\widetilde{P}} \\
q & =\underbrace{\mathbf{v}_{\perp}^{+} \cdot \mathbf{i}_{Q}^{+, r e f}+\mathbf{v}_{\perp}^{-} \cdot \mathbf{i}_{Q}^{-, r e f}}_{\bar{Q}}
\end{aligned}
$$

giving oscillation-free reactive power and oscillating active power with zero average value. Nevertheless, this method cannot provide active power with non-zero average value. In order to provide a certain amount of active power, active current reference (12) is changed to [43]:

$$
\mathbf{i}_{P}^{r e f}=\frac{P^{r e f}}{\left|\mathbf{v}^{+}\right|^{2}+\left|\mathbf{v}^{-}\right|^{2}}\left(\mathbf{v}^{+}+\mathbf{v}^{-}\right)
$$

Consequently, with current references (21) and (13), the instantaneous output active and reactive power become (14) and (20) respectively, achieving constant reactive power and non-zero-average-value active power. In addition, a set of unbalanced current is injected to the grid and oscillations in twice fundamental frequency are registered in active power.

\section{E. Flexible Oscillating Power Control}

In order to obtain a compromise among the aforementioned three control strategies, two extra flexible coefficients $k_{p}$ and $k_{q}$ that can be adjusted within a specific range are introduced in current references as [14], [35], [44], [45]:

$$
\begin{aligned}
& \mathbf{i}_{P}^{\text {ref }}=\frac{P^{r e f}}{\left|\mathbf{v}^{+}\right|^{2}+k_{p}\left|\mathbf{v}^{-}\right|^{2}}\left(\mathbf{v}^{+}+k_{p} \mathbf{v}^{-}\right) \\
& \mathbf{i}_{Q}^{r e f}=\frac{Q^{r e f}}{\left|\mathbf{v}^{+}\right|^{2}+k_{q}\left|\mathbf{v}^{-}\right|^{2}}\left(\mathbf{v}_{\perp}^{+}+k_{q} \mathbf{v}_{\perp}^{-}\right)
\end{aligned}
$$

Given (22) and (23), the constant active and reactive power terms in (5) and (6) are equal to $P^{r e f}$ and $Q^{\text {ref }}$ respectively while the oscillating terms can be further expressed by:

$$
\begin{gathered}
\widetilde{P}=\underbrace{\frac{\left(1+k_{p}\right) P^{r e f}}{D_{p}} \mathbf{v}^{+} \mathbf{v}^{-}}_{\widetilde{P_{p}}}+\underbrace{\frac{\left(1-k_{q}\right) Q^{r e f}}{D_{q}} \mathbf{v}_{\perp}^{+} \mathbf{v}^{-}}_{\widetilde{P_{q}}} \\
\widetilde{Q}=\underbrace{\frac{\left(1+k_{q}\right) Q^{r e f}}{D_{q}} \mathbf{v}_{\perp}^{+} \mathbf{v}_{\perp}^{-}}_{\widetilde{Q_{q}}}+\underbrace{\frac{\left(1-k_{p}\right) P^{r e f}}{D_{p}} \mathbf{v}^{+} \mathbf{v}_{\perp}^{-}}_{\widetilde{Q_{p}}}
\end{gathered}
$$

where $\widetilde{P_{p}}$ and $\widetilde{Q_{p}}$ denote the oscillating power terms contributed by injecting active power while $\widetilde{P}_{q}$ and $\widetilde{Q_{q}}$ are oscillating power terms originated from injecting reactive power. Denominators $D_{p}$ and $D_{q}$ are given by:

$$
D_{p}=\left|\mathbf{v}^{+}\right|^{2}+k_{p}\left|\mathbf{v}^{-}\right|^{2} \quad D_{q}=\left|\mathbf{v}^{+}\right|^{2}+k_{q}\left|\mathbf{v}^{-}\right|^{2}
$$

Therefore, the oscillating active and reactive power can be flexibly adjusted by changing $k_{p}$ and $k_{q}$. When $k_{p}=k_{q}=0$, it is equivalent to balanced current control strategy; when $k_{p}=-1$ and $k_{q}=1$, constant active power strategy is achieved while constant reactive power strategy is obtained by choosing $k_{p}=1$ and $k_{q}=-1$. A compromise among these three strategies can be made by choosing other combinations of $k_{p}$ and $k_{q}$. According to [45], a reduction of oscillations in either active power or reactive power will give rise to oscillations in the other one. This indicates that oscillation-free active and reactive power cannot be achieved simultaneously with this control strategy.

\section{F. Constant Active-Reactive Power Control}

As the name suggests, this control strategy is able to deliver constant active power and constant reactive power at the same time under unbalanced conditions with current references [29], [35], [46]:

$$
\begin{aligned}
& \mathbf{i}_{P}^{r e f}=\frac{P^{r e f}}{|\mathbf{v}|^{2}} \mathbf{v} \\
& \mathbf{i}_{Q}^{r e f}=\frac{Q^{r e f}}{|\mathbf{v}|^{2}} \mathbf{v}_{\perp}
\end{aligned}
$$

Therefore, the instantaneous power at the PCC is simplified as:

$$
\begin{aligned}
p & =\underbrace{\mathbf{v}^{+} \cdot \mathbf{i}_{P}^{\text {ref }}}_{\bar{P}} \\
q & =\underbrace{\mathbf{v}_{\perp}^{+} \cdot \mathbf{i}_{Q}^{\text {ref }}}_{\bar{Q}}
\end{aligned}
$$

which facilitates the highest degree of control over instantaneous power since the power is oscillation-free and equal to its reference. However, under unbalanced conditions, the value of $|\mathbf{v}|$ in the denominator of (27) and (28) will exhibit oscillation at twice the fundamental frequency, resulting in non-sinusoidal fault current with higher-order component. 


\section{VOLTAGE-SUPPORT-ORIENTED CONTROL STRATEGY}

As grid codes require converter-based generation to inject reactive current to support grid voltage under voltage dips, control strategies under unbalanced grid faults can also be developed based on regulation of phase voltage. This section firstly presents voltage support concept using symmetrical sequence theory. Secondly, two general control strategies that can adjust the relative relationship between positive- and negative-sequence power either semi-flexibly or flexibly are presented, followed by a review on selecting the values of flexible coefficients. Finally, the relationship between different flexible control strategies are discussed.

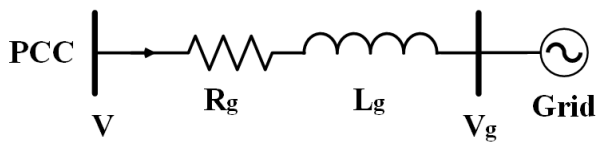

Fig. 1: Simplified power system seen from the PCC

\section{A. Voltage Support Concept}

For a simplified power system seen from the PCC given in Fig. 1, the mathematical relationship between the PCC voltage and grid voltage can be expressed by:

$$
\mathbf{v}=\mathbf{v}_{g}+R_{g} \mathbf{i}+L_{g} \frac{\mathrm{d} \mathbf{i}}{\mathrm{d} t}
$$

By using the magnitudes of symmetrical components and neglecting grid resistance, (31) can be split into two equations:

$$
\begin{aligned}
& \left|\mathbf{v}^{+}\right|=\left|\mathbf{v}_{g}^{+}\right|+\omega L_{g}\left|\mathbf{i}_{Q}^{+}\right| \\
& \left|\mathbf{v}^{-}\right|=\left|\mathbf{v}_{g}^{-}\right|-\omega L_{g}\left|\mathbf{i}_{Q}^{-}\right|
\end{aligned}
$$

According to (32) and (33), the PCC positive-sequence voltage can be boosted by injecting positive-sequence reactive current, while injecting negative-sequence reactive current can help mitigate PCC voltage unbalance [47]-[50]. Referred to the instantaneous reactive power in (6), the constant part $\bar{Q}$ consists of two terms, one contributed by positive-sequence reactive current and one oriented from negative-sequence reactive current. Then, positive- and negative-sequence reactive power can be defined as:

$$
Q^{+}=\mathbf{v}_{\perp}^{+} \cdot \mathbf{i}^{+} \quad Q^{-}=\mathbf{v}_{\perp}^{-} \cdot \mathbf{i}^{-}
$$

As indicated by (32) to (34), grid voltage support can be realized in two different aspects. If only positive-sequence reactive power is injected under unbalanced faults, the PCC voltage will be raised equally in each phase compared with grid voltage $\left|\mathbf{v}_{g}^{+}\right|$. On the other hand, PCC voltage unbalance can be maximumly compensated by injecting only negativesequence reactive power.

For low-voltage grids with high penetration of gridconnected converters, where the network impedance is more resistive, the voltage support concept explained by (32) and (33) cannot work efficiently [43], [51]. With grid inductance ignored, (31) can be expressed by two equations using symmetrical components:

$$
\begin{aligned}
& \left|\mathbf{v}^{+}\right|=\left|\mathbf{v}_{g}^{+}\right|+R_{g}\left|\mathbf{i}_{P}^{+}\right| \\
& \left|\mathbf{v}^{-}\right|=\left|\mathbf{v}_{g}^{-}\right|+R_{g}\left|\mathbf{i}_{P}^{-}\right|
\end{aligned}
$$

which indicates that injecting positive-sequence active power can help boost positive-sequence voltage at the PCC while reducing the amount of negative-sequence active power helps mitigate PCC voltage unbalance for resistive network.

Therefore, converter control strategies under unbalanced faults can be developed based on controlling the relative relationship between positive- and negative-sequence power to combine the effect of supporting phase voltage equally and compensating for voltage unbalance.

\section{B. Semi-flexible Positive- and Negative-sequence Power Con- trol}

In order to flexibly adjust the relative relationship between positive- and negative- sequence reactive power, the reactive current reference (23) is modified by introducing flexible coefficients as [47], [48], [52], [53]:

$$
\mathbf{i}_{Q}^{r e f}=\frac{k_{q} \mathbf{v}_{\perp}^{+}+\left(1-k_{q}\right) \mathbf{v}_{\perp}^{-}}{k_{q}\left|\mathbf{v}^{+}\right|^{2}+\left(1-k_{q}\right)\left|\mathbf{v}^{-}\right|^{2}} Q^{r e f}
$$

If this flexibility is extended to active current in the same manner, active current reference becomes:

$$
\mathbf{i}_{P}^{r e f}=\frac{k_{p} \mathbf{v}^{+}+\left(1-k_{p}\right) \mathbf{v}^{-}}{k_{p}\left|\mathbf{v}^{+}\right|^{2}+\left(1-k_{p}\right)\left|\mathbf{v}^{-}\right|^{2}} P^{r e f}
$$

With (37) and (38), the instantaneous power at PCC can be obtained as:

$$
\begin{aligned}
p= & \underbrace{\frac{k_{p} P^{r e f}}{D_{p}} \cdot\left|\mathbf{v}^{+}\right|^{2}}_{P^{+}}+\underbrace{\frac{\left(1-k_{p}\right) P^{r e f}}{D_{p}} \cdot\left|\mathbf{v}^{-}\right|^{2}}_{P^{-}} \\
& +\underbrace{\frac{P^{r e f}}{D_{p}} \cdot \mathbf{v}^{+} \mathbf{v}^{-}}_{\widetilde{P_{p}}}+\underbrace{\frac{\left(2 k_{q}-1\right) Q^{r e f}}{D_{p}} \cdot \mathbf{v}_{\perp}^{+} \mathbf{v}^{-}}_{\widetilde{P_{q}}} \\
q= & \underbrace{\frac{k_{q} Q^{r e f}}{D_{q}} \cdot\left|\mathbf{v}_{\perp}^{+}\right|^{2}}_{Q^{+}}+\underbrace{\frac{\left(1-k_{q}\right) Q^{r e f}}{D_{q}} \cdot\left|\mathbf{v}_{\perp}^{-}\right|^{2}}_{Q^{-}} \\
& +\underbrace{\frac{Q^{r e f}}{D_{q}} \cdot \mathbf{v}_{\perp}^{+} \mathbf{v}_{\perp}^{-}}_{\widetilde{Q_{q}}}+\underbrace{\frac{\left(2 k_{p}-1\right) P^{r e f}}{D_{q}} \cdot \mathbf{v}^{+} \mathbf{v}_{\perp}^{-}}_{\widetilde{Q_{p}}}
\end{aligned}
$$

where denominators $D_{p}$ and $D_{q}$ are given as:

$$
\begin{aligned}
& D_{p}=k_{p}\left|\mathbf{v}^{+}\right|^{2}+\left(1-k_{p}\right)\left|\mathbf{v}^{-}\right|^{2} \\
& D_{q}=k_{q}\left|\mathbf{v}^{+}\right|^{2}+\left(1-k_{q}\right)\left|\mathbf{v}^{-}\right|^{2}
\end{aligned}
$$

Thus the reference power is satisfied via injecting positive- and negative-sequence power at the same time under unbalanced faults, and the average value of oscillating power terms are 
zero. By comparing the relationship between positive- and negative-sequence power, there are:

$$
\frac{P^{+}}{P^{-}}=\frac{k_{p}}{1-k_{p}} \cdot \frac{\left|\mathbf{v}^{+}\right|^{2}}{\left|\mathbf{v}^{-}\right|^{2}} \quad \frac{Q^{+}}{Q^{-}}=\frac{k_{q}}{1-k_{q}} \cdot \frac{\left|\mathbf{v}_{\perp}^{+}\right|^{2}}{\left|\mathbf{v}_{\perp}^{-}\right|^{2}}
$$

which indicates that the relationship between of positive- and negative-sequence power relies on not only the values of $k_{p}$ and $k_{q}$, but also grid fault characteristics. This explains why this control strategy is called "semi-flexible" in this paper. It should be mentioned that reactive power is injected via only positive-sequence when $k_{q}=1$, and only negative-sequence if $k_{q}=0$ regardless of fault characteristics. The same conclusion is also valid for active power.

\section{Flexible Positive- and Negative-sequence Power Control}

According to [29], [44], [45], [49], [50], [54]-[57], flexible coefficients $k_{p}$ and $k_{q}$ can also be included in current references such as:

$$
\begin{aligned}
& \mathbf{i}_{P}^{r e f}=k_{p} \frac{P^{r e f}}{\left|\mathbf{v}^{+}\right|^{2}} \mathbf{v}^{+}+\left(1-k_{p}\right) \frac{P^{r e f}}{\left|\mathbf{v}^{-}\right|^{2}} \mathbf{v}^{-} \\
& \mathbf{i}_{Q}^{r e f}=k_{q} \frac{Q^{r e f}}{\left|\mathbf{v}^{+}\right|^{2}} \mathbf{v}_{\perp}^{+}+\left(1-k_{q}\right) \frac{Q^{r e f}}{\left|\mathbf{v}^{-}\right|^{2}} \mathbf{v}_{\perp}^{-}
\end{aligned}
$$

Then, the instantaneous power at the PCC is expressed by:

$$
\begin{aligned}
& p=\underbrace{\frac{k_{p} P^{r e f}}{\left|\mathbf{v}^{+}\right|^{2}} \cdot\left|\mathbf{v}^{+}\right|^{2}}_{P^{+}}+\underbrace{\frac{\left(1-k_{p}\right) P^{r e f}}{\left|\mathbf{v}^{-}\right|^{2}} \cdot\left|\mathbf{v}^{-}\right|^{2}}_{P^{-}} \\
& +\underbrace{\left(\frac{k_{p} P^{r e f}}{\left|\mathbf{v}^{+}\right|^{2}}+\frac{\left(1-k_{p}\right) P^{r e f}}{\left|\mathbf{v}^{-}\right|^{2}}\right) \mathbf{v}^{+} \cdot \mathbf{v}^{-}}_{\widetilde{P_{p}}} \\
& +\underbrace{\left(\frac{k_{q} Q^{r e f}}{\left|\mathbf{v}^{+}\right|^{2}}-\frac{\left(1-k_{q}\right) Q^{r e f}}{\left|\mathbf{v}^{-}\right|^{2}}\right) \mathbf{v}_{\perp}^{+} \cdot \mathbf{v}^{-}}_{\widetilde{P_{q}}} \\
& q=\underbrace{\frac{k_{q} Q^{\text {ref }}}{\left|\mathbf{v}^{+}\right|^{2}} \cdot\left|\mathbf{v}_{\perp}^{+}\right|^{2}}_{Q^{+}}+\underbrace{\frac{\left(1-k_{q}\right) Q^{r e f}}{\left|\mathbf{v}^{-}\right|^{2}} \cdot\left|\mathbf{v}_{\perp}^{-}\right|^{2}}_{Q^{-}} \\
& +\underbrace{\left(\frac{k_{q} Q^{r e f}}{\left|\mathbf{v}^{+}\right|^{2}}+\frac{\left(1-k_{q}\right) Q^{r e f}}{\left|\mathbf{v}^{-}\right|^{2}}\right) \mathbf{v}_{\perp}^{+} \cdot \mathbf{v}_{\perp}^{-}}_{\widetilde{Q_{q}}} \\
& +\underbrace{\left(\frac{k_{p} P^{r e f}}{\left|\mathbf{v}^{+}\right|^{2}}-\frac{\left(1-k_{p}\right) P^{r e f}}{\left|\mathbf{v}^{-}\right|^{2}}\right) \cdot \mathbf{v}^{+} \mathbf{v}_{\perp}^{-}}_{\widetilde{Q_{p}}}
\end{aligned}
$$

which enables a direct control over the relative relationship between positive- and negative-sequence power. This relationship is only determined by flexible coefficients regardless of grid fault characteristics since:

$$
\frac{P^{+}}{P^{-}}=\frac{k_{p}}{1-k_{p}} \quad \frac{Q^{+}}{Q^{-}}=\frac{k_{q}}{1-k_{q}}
$$

which explains why this control strategy is entitled "flexible" rather than "semi-flexible" in this paper.

\section{Selection of Flexible Coefficients}

As flexible coefficients are scalar quantities, there exists infinite combinations of $k_{p}$ and $k_{q}$. By carefully selecting their values, some extra objectives can be realized.

With either semi-flexible or flexible positive- and negativesequence control strategy, $k_{q}$ together with $Q^{r e f}$ are either calculated using on-line measurements [47], [49] or generated through PI controllers [48] aiming to regulate phase voltage at the PCC so that:

$$
\min \left\{V_{a}, V_{b}, V_{c}\right\} \geq V_{L} \quad \max \left\{V_{a}, V_{b}, V_{c}\right\} \leq V_{H}
$$

where $V_{a}, V_{b}$ and $V_{c}$ are the amplitudes of voltage in each phase; while $V_{L}$ and $V_{H}$ correspond to a predefined lower and higher voltage boundary respectively. It is worth noticing that the methods in [47] and [49] require an accurate estimation of the Thevenin equivalent circuit of the AC grid. In [58], positive- and negative-sequence reactive power is controlled according to:

$$
\frac{Q^{+}}{Q^{-}}=\frac{\left(V_{\text {nom }}-\left|\mathbf{v}^{+}\right|\right)\left|\mathbf{v}^{+}\right|}{\left|\mathbf{v}^{-}\right|^{2}}
$$

where $V_{\text {nom }}$ represents the nominal grid voltage, so that this relationship is similar to that of an ideal synchronous capacitor. This indicates that $k_{q}$ is determined by the grid fault characteristics. As the grid side resistance is ignored in the above studies, voltage support can only be achieved by injecting reactive power. Therefore, the strategy on choosing $k_{p}$ is not included.

In [51], a modification is made to (37) and (38) by involving the grid resistance into current reference calculation, so that flexible voltage support is also effective for a resistive grid. However, the value of flexible coefficients are simply selected. With the grid resistance considered, a most recent work [50] proposes two strategies generating $k_{p}$ and $k_{q}$ for (44) and (45) in order to compensate for the grid unbalanced voltage. One strategy obtains $k_{p}$ and $k_{q}$ by controlling negative-sequence current contributed by converters in phase with grid side negative-sequence current so that the voltage unbalance is minimized, where the $R / X$ ratio of the grid is required to realize the control objective. The other strategy minimizes active power oscillation by solving an optimization problem on-line, where $k_{p}$ and $k_{q}$ become optimized control parameters. This indicates that "voltage-support-oriented" control strategy can also exhibit similar effects as "power-characteristic-oriented" control strategy with proper $k_{p}$ and $k_{q}$. The relationship between "power-characteristic-oriented" and "voltage-supportoriented" control strategy will be discussed in the subsequent section.

\section{E. Relationship between Flexible Control Strategies}

Even though flexible positive- and negative-sequence power control strategy is applied in [50], [55], [56], the $k_{p}-k_{q}$ joint strategies reported in these studies also exhibit some features related to power-characteristic-oriented control strategies, which suggests that there may be a relationship between different flexible control strategies. In [56], the joint strategy can be either $k_{p}=k_{q}=k$ or $k_{p}=1-k_{q}=k(0 \leq k \leq 1)$. The 
same-sign-coefficient strategy reduces oscillations in active and reactive power at the same time when $k$ tends towards 0 ; while for the complementary-coefficient strategy, oscillation reduction in either active or reactive power will deteriorate the other. One strategy reported in [50] aims at reducing oscillations in output active power by solving an optimisation problem on-line. In [55], the average active and reactive power of each phase can be equalized by choosing:

$$
k_{p}=k_{q}=\frac{1}{1-\left|\mathbf{v}^{+}\right|^{2} /\left|\mathbf{v}^{-}\right|^{2}}
$$

For flexible positive- and negative-sequence power control, it is equivalent to balanced current control strategy if $k_{p}=$ $k_{q}=1$ is selected. Constant active power strategy is obtained by choosing:

$$
k_{p}=\frac{\left|\mathbf{v}^{+}\right|^{2}}{\left|\mathbf{v}^{+}\right|^{2}-\left|\mathbf{v}^{-}\right|^{2}} \quad k_{q}=\frac{\left|\mathbf{v}^{+}\right|^{2}}{\left|\mathbf{v}^{+}\right|^{2}+\left|\mathbf{v}^{-}\right|^{2}}
$$

Similarly, constant reactive power is achieved by swapping the values of $k_{p}$ and $k_{q}$ obtained by (52). In general, if the relationship between two coefficients is chosen as:

$$
\begin{aligned}
1 / k_{p}+1 / k_{q} & =2 \\
\frac{\left|\mathbf{v}^{+}\right|^{2}}{\left|\mathbf{v}^{+}\right|^{2}+\left|\mathbf{v}^{-}\right|^{2}} \leq k_{p, q} & \leq \frac{\left|\mathbf{v}^{+}\right|^{2}}{\left|\mathbf{v}^{+}\right|^{2}-\left|\mathbf{v}^{-}\right|^{2}}
\end{aligned}
$$

flexible positive- and negative-sequence control is the same as flexible oscillating power control with $k_{p}=-k_{q}(-1 \leq$ $\left.k_{p, q} \leq 1\right)$ joint strategy.

Therefore, as long as the joint strategy is determined in either of these two flexible control strategies, there exists fixed values or expressions of coefficients in the other one so that they are equivalent to each other. In [58], a compromise between constant active power strategy and (50) is also documented with the idea of flexible control. This further indicates that flexible control strategies can be achieved in various ways depending on how flexible coefficients are included and selected in current references. In fact, satisfying the objective of one control strategy with certain $k_{p}$ and $k_{q}$ may either help achieve or deteriorate the objective of another. This explains why one group of control strategies may also exhibit similar features of the other group under some conditions.

\section{Converter Current Limit}

Considering semiconductor capabilities, the current flowing through converters should be restricted. Under grid unbalanced faults, the accomplishment of certain control strategies may push the current in some phases above its limit, which can trip VSC undesirably. However, most of the studies leave converter current limit issue out when control strategies are proposed.

Ideally, negative-sequence current doesn't exsit for threephase balanced faults, which makes current limiter design straightforward [59], [60]. If transformed into synchronous reference frame, the converter current limit $I_{\max }$ can be restricted by:

$$
I_{\max }=\sqrt{i_{d}^{2}+i_{q}^{2}}
$$

If reactive current injection takes the first priority during faults, $i_{d}$ can be determined by (55) once $i_{q}$ is set in accordance with the grid codes. During unbalanced faults, it is still possible to apply (55) if balanced current strategy is adopted, as the negative-sequence current is always regulated to be zero.

However, converter current limit becomes more complicated if unbalanced current is injected, as both positive- and negative-sequence current should be restricted in proper ways and this strongly correlates with control strategies. In order to restrict the current in each individual phase, converter current limit should be specifically analysed for each control strategy [29], [61]. Constant active power strategy is dealt with in [37], [38], [40], [62]. Considering the fact that an extremely high fault current may be required to keep active power level unchanged during severe voltage dips, current limit is imposed by restricting active power in [37], [38], [62]. It is worth noticing that there is a discontinuity in (12) when $\left|\mathbf{v}^{+}\right|=\left|\mathbf{v}^{-}\right|$, which can lead to infinite active current reference. Therefore, a switching factor is introduced in [40] so that the control strategy is shifted to balanced current operation under this scenario. However, all of these studies do not consider reactive current injection.

In [42], procedures to calculate the maximum current amplitude among three phases under unbalanced faults are given for constant active power and constant reactive power strategy, based on which the maximum reactive power that can be delivered without exceeding current limit is obtained. The method proposed in [63] aims to minimize DC bus voltage oscillations, where reactive power reference is restricted considering not only current limit but also upper voltage limit and DC bus voltage oscillation limit. However, these methods are only applicable if active power reference is set to zero and the discontinuity in (13) caused by $\left|\mathbf{v}^{+}\right|=\left|\mathbf{v}^{-}\right|$for constant reactive power strategy is not addressed. As it is not the objective of one single converter to damp the voltage unbalance or increase the voltage to nominal level, the required reactive power to achieve phase voltage regulation according to (49) may be extremely high, thus resulting in over-current. Therefore, with active power reference set to zero, the amplitude of the injected current in each phase $I_{m}(m=a, b, c)$ is mathematically derived using on-line measurement in [49]. Then, a scale factor $I_{\max } / \max \left\{I_{m}\right\}$ is multiplied to the desired $Q^{+}$and $Q^{-}$to obtain saturated reactive power $Q_{s}^{+}$and $Q_{s}^{-}$. The final reactive power references are generated by two selectors according to:

$$
Q^{+r e f}=\min \left\{Q_{s}^{+}, Q^{+}\right\} \quad Q^{-r e f}=\min \left\{Q_{s}^{-}, Q^{-}\right\}
$$

which is able to restrict current in each phase and the voltage support target cannot be accomplished whenever $Q_{s}^{+}$or $Q_{s}^{-}$ is selected in (56). With semi-flexible positive- and negativesequence reactive power control in [48], the expression of $\max \left\{I_{m}\right\}$ as a function of $Q^{r e f}$ and $k_{q}$ is derived. Once $I_{\max }$ is given, the maximum reactive power $Q_{\max }$ can be delivered without overpassing current limit can be calculated by solving:

$$
\max \left\{I_{a}, I_{b}, I_{c}\right\}=I_{\max }
$$

If active power and reactive power are injected simultaneously through unbalanced current, none of the methods reviewed above is valid as the superposition of active and 
reactive current will raise current in some phases during a certain period of time. With flexible control over positive- and negative-sequence reactive power, a detailed analysis of the current amplitude in each phase is provided in [53] considering positive-sequence active power. In [54], the current amplitude of each individual phase is mathematically derived taking both flexible coefficients $k_{p}$ and $k_{q}$ into account for flexible positive- and negative-sequence power control strategy. As graphically illustrated in [60], which phase has the peak current and its amplitude varies depending on the grid fault characteristics, which makes it even more complicated to design a unique converter current limiter that is valid for all kinds of grid unbalanced faults if both active and reactive power are injected. Based on [53], [54], [60], a recent work [55] applying flexible positive- and negative-sequence power control strategy derives the expressions of active power and reactive power in terms of grid conditions, flexible coefficients and converter current rating. First priority of injecting either active power or reactive power can be freely decided and the converter current is restrained in each phase with maximizing the utilization of converter power capacity.

It can be seen that all the control strategies under unbalanced faults are developed based on some specific objectives, the realization of which may lead to current in some phases above its rating $I_{\max }$. This means that if current in all phases is controlled within the constraint, the desired objective of its control strategy could be compromised. Even if the expected characteristic of certain variables can be achieved, there will be an reduction in the available active or reactive power.

Based on the available literature, injecting active and reactive power simultaneously by maximizing the utilization of converter power capacity is gaining increasingly attention. If active power injection takes the first priority under fault conditions, as long as the active power reference is determined, the converter current margin left can be used to inject reactive power to improve grid support services [64] and vice versa if reactive power injection takes the first priority. This indicates that the values of active and reactive power reference should be determined or calculated in a fast and accurate way under grid unbalanced faults. However, the computing procedure are generally complex and it is even more sophiscated to be implemented if flexible coefficient $k_{p}$ and $k_{q}$ are involved [55], [60]. Therefore, it might be more reasonable to select a certain control stategy based on system conditions as presented in [64] in the future for the sake of simplicity.

It is also worth noticing that the work in [47], [49], [50] and [63] considering phase over-voltage issue requires a good knowledge of the grid impedance. However, the simulation and experimental results are given for a simple system where the converter is connected to a programmable source with source impedance known in advance. As the type and location of faults and fault impedances cannot be predicted, it is challenging to estimate the equivalent grid impedance at the PCC accurately and fast for a large power system with high penetration of renewable generation. Therefore, the feasibility of these methods needs further investigation and validation for a larger power system with various of faults applied.

\section{Case Studies}

In order to illustrate the main differences among various control strategies, this section presents and discusses the behaviour of a grid-connected VSC system subject to grid unbalanced faults as show in Fig 2. The short circuit ratio at the PCC is 10 and the converter current limit is selected as 1.2 per unit. The VSC is delivering power at its full capacity with unity power factor prior to the fault. With reactive power injection prioritized under faults for all cases, the reactive power reference is assumed to be generated according to $Q^{r e f}=\left|\mathbf{v}^{+}\right| \cdot I_{Q}$, where $I_{Q}$ is obtained in accordance with Fig. 3 using positive-sequence voltage at the PCC, while the converter current margin left is utilized for active power injection. All the measurements are taken from the low voltage-side of the transformer. The simulations are performed in Real Time Digital Simulator (RTDS).

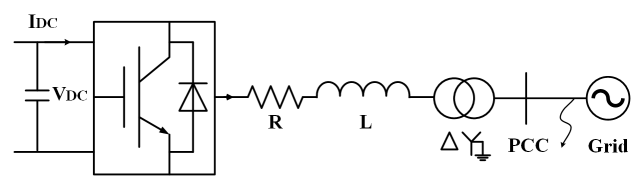

Fig. 2: Configuration of a grid-connected VSC system

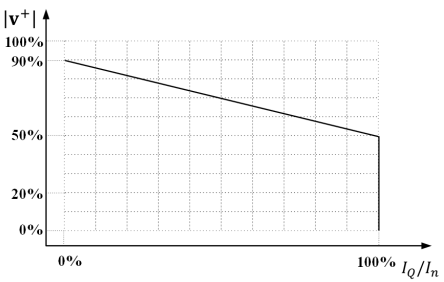

Fig. 3: Requirements of reactive curernt injection during voltage dips [65]

\section{A. Power-characteristic-oriented Control Strategy}

With constant active power, balanced current and constant reactive power control strategies applied, a phase-A-g fault with $10 \mathrm{ohm}$ fault resistance is applied at the PCC at zero time instant. The corresponding three-phase output current and output power in per unit value are plotted in Fig. 4(a)(c) without converter current limit and in Fig. 4(d)-(f) with converter current limit respectively. By comparing Fig. 4(a)(c), a reduction of oscillations in either active or reactive power will deteriorate the other. With current limit of 1.2 p.u. in each phase, the output active power is reduced properly as shown in Fig. 4(d)-(f) compared to Fig. 4(a)-(c). It is worth noticing that with constant reactive power control strategy, the average value of the output active power is reduced to zero, as the converter current limit has already been reached by only injecting reactive power. This indicates that not only active power but also reactive power is reduced to comply with the current limit.

Constant active power, balanced current and constant reactive power control strategies are three special cases of the flexible oscillating power control strategy. A compromise 


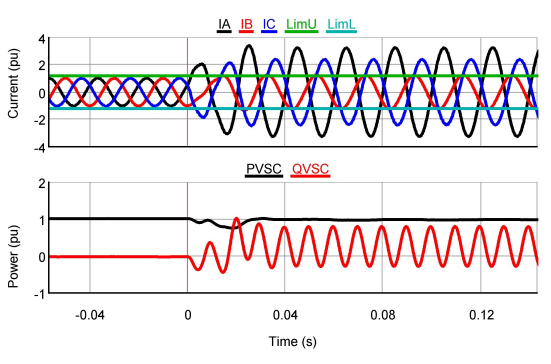

(a) Constant active power without I limit

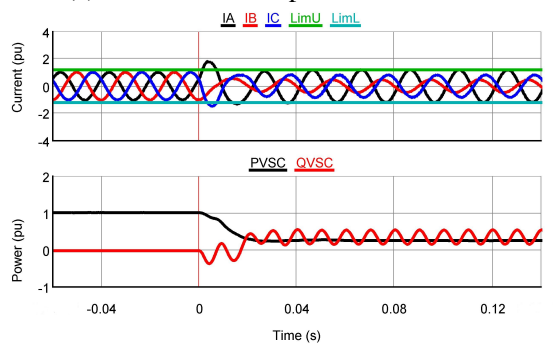

(d) Constant active power with I limit

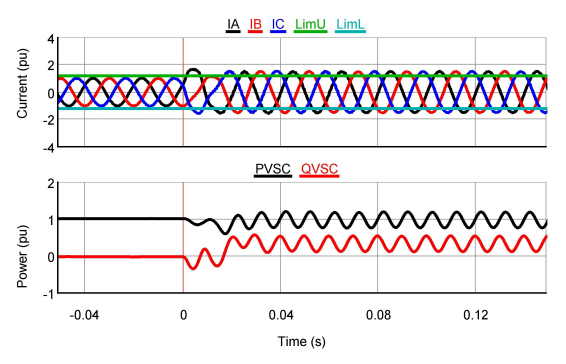

(b) Balanced current without I limit

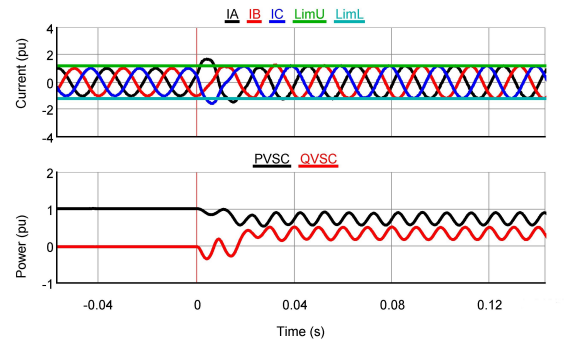

(e) Balanced current with I limit

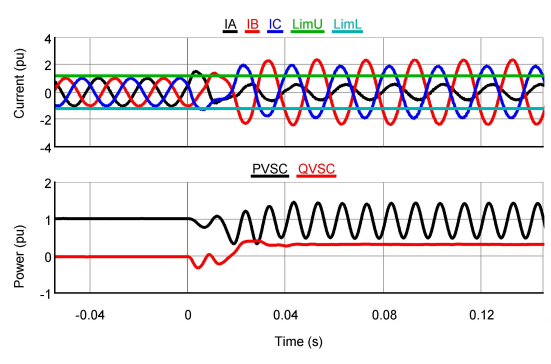

(c) Constant reactive power without I limit

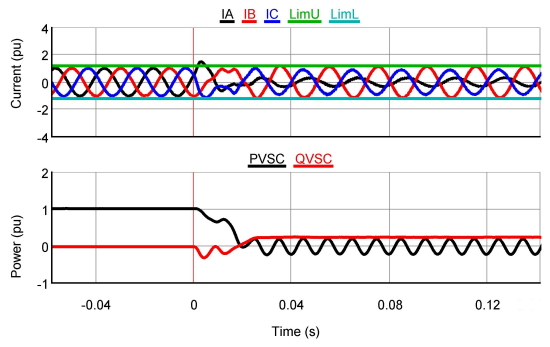

(f) Constant reactive power with I limit

Fig. 4: Simulation of VSC behaviour with power-characteristic-oriented control strategy

TABLE II

Features of Flexible Oscillating Power Control

\begin{tabular}{l|l|l|l|l|l}
\hline \hline $\begin{array}{l}\text { Control } \\
\text { Strategy }\end{array}$ & $\begin{array}{l}\text { Balanced } \\
\text { Current }\end{array}$ & $\begin{array}{l}\text { P } \\
\text { Oscillations }\end{array}$ & $\begin{array}{l}\text { O } \\
\text { Oscillations }\end{array}$ & P Delivery & Q Delivery \\
\hline Constant $P$ & No & No & Yes & Medium & High \\
\hline Balanced $I$ & Yes & Yes & Yes & High & High \\
\hline Constant $Q$ & No & Yes & No & Low & Low \\
\hline \hline
\end{tabular}

among them can be made by choosing different combinations of $k_{p}$ and $k_{q}$. As the output active power is directly correlated to DC link voltage, constant active power control strategy can help mitigate the DC link voltage oscillations. However, the active current reference generated by (12) can be pushed to an extremely high value when $\left|\mathbf{v}^{+}\right| \approx\left|\mathbf{v}^{-}\right|$if $P^{r e f}$ is not reduced properly. Even if $P^{r e f}$ is reduced, there is still a risk of generating current reference with high value as $\left|\mathbf{v}^{+}\right|$and $\left|\mathbf{v}^{-}\right|$ come from measurements and the transient or noise existed may lead to $\left|\mathbf{v}^{+}\right|=\left|\mathbf{v}^{-}\right|$at some instants, which also applies to constant reactive power strategy. This discontinuity should be carefully dealt with when calculating current references. In addition, as $Q_{r e f}$ is obtained according to a pre-defined profile in Fig. 3, a reduction in $Q_{r e f}$ to restrain output current means that the assumed reactive power requirement cannot be satisfied any more. Therefore, constant reactive power control strategy has lower capability of delivering active and reactive power with reactive power injection prioritized. Table II summarizes the main differences among these special cases of flexible oscillating power control strategy considering converter current limit.

In order to see the impact of power-characteristic-oriented control strategies on voltage, two scenarios are simulated for flexible oscillating power control with $k_{p}=-k_{q}=k$ considering 1.2 p.u. converter current limit. In scenario I, the

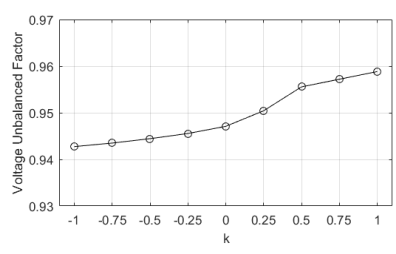

(a) Scenario I: inductive grid

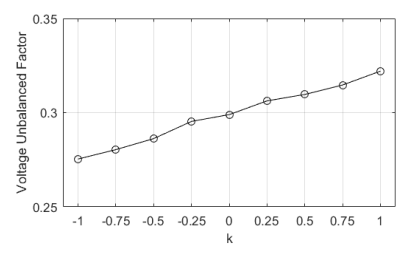

(b) Scenario II: resistive grid
Fig. 5: Voltage unbalanced factor for flexible oscillating power control with $k_{p}=-k_{q}=k$

grid impedance angle is $85^{\circ}$ and a solid phase-A-g fault is applied at the PCC, which represents an inductive-grid case. In scenario II, the grid impedance angle is $5^{\circ}$ and a phase-A$\mathrm{g}$ fault with $25 \mathrm{ohm}$ resistance is applied at the PCC, which imitates a resistive grid as seen from the PCC. By increasing $k_{p}$ from -1 to 1 with 0.25 step, the voltage unbalanced $n$ factor $\left(\left|\mathbf{v}^{-}\right| /\left|\mathbf{v}^{+}\right|\right)$during the fault are plotted in Fig. 5, which indicates that the voltage unbalance is deteriorated when control strategy is moving from constant active power towards constant reactive power strategy for both scenarios.

\section{B. Voltage-support-oriented Control Strategy}

With flexible positive- and negative-sequence power control adopted, a phase-A-g fault with $10 \mathrm{ohm}$ fault resistance is applied at the PCC at zero time instant. The corresponding three-phase output current, output power and sequence reactive power in per unit value are plotted in Fig. 6(a)-(c) without converter current limit and in Fig. 6(d)-(f) with converter current limit. It can be observed from Fig. 6(a)-(c) or Fig. 6(d)-(f) that the amount of positive-sequence reactive power is decreasing while the the amount of negative-sequence reactive power is increasing as $k_{q}$ is changing from 1 to 0 . When 


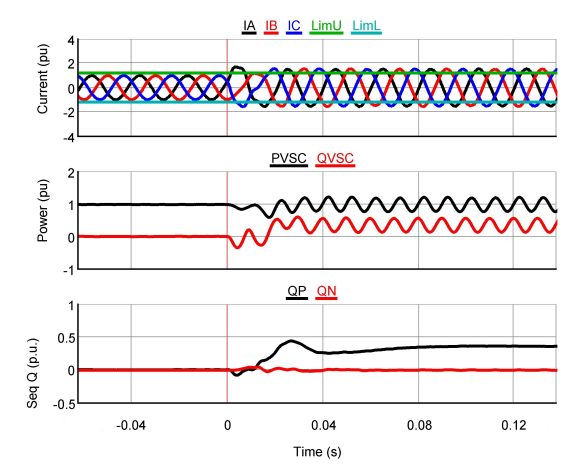

(a) $k_{p}=1$ and $k_{q}=1$ without I limit

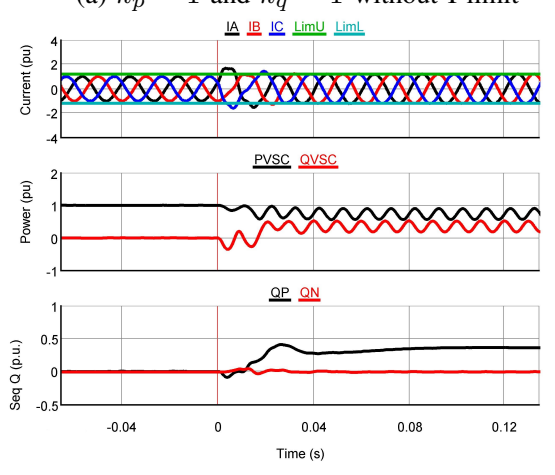

(d) $k_{p}=1$ and $k_{q}=1$ with I limit

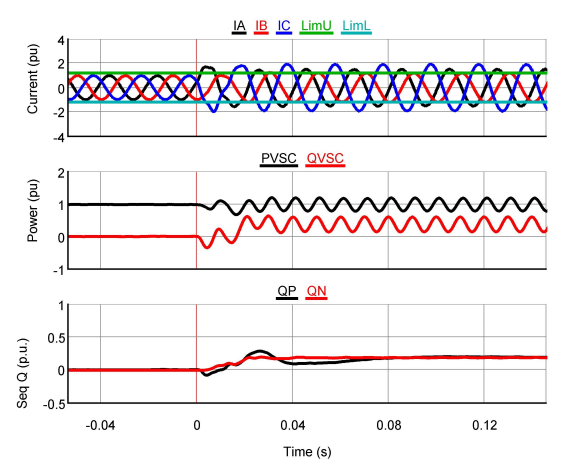

(b) $k_{p}=1$ and $k_{q}=0.5$ without I limit
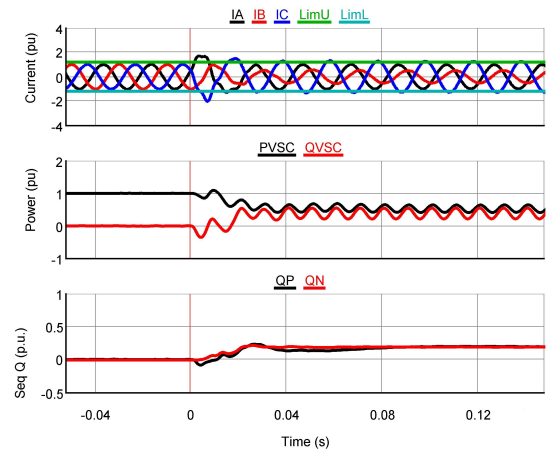

(e) $k_{p}=1$ and $k_{q}=0.5$ with I limit

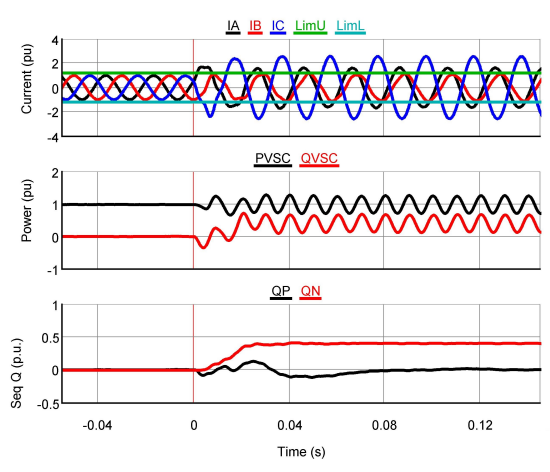

(c) $k_{p}=1$ and $k_{q}=0$ without I limit
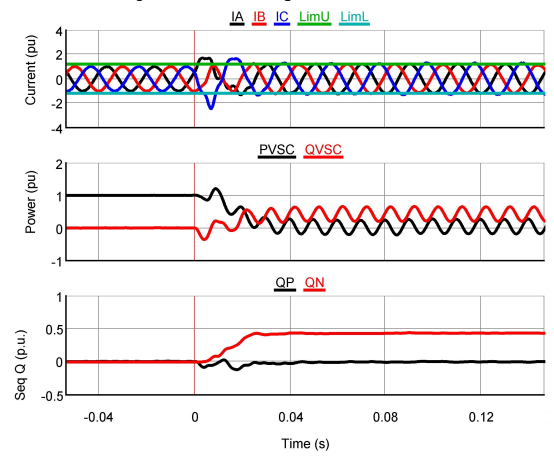

(f) $k_{p}=1$ and $k_{q}=0$ with I limit

Fig. 6: Simulation of VSC behaviour with flexible positive- and negative-sequence power control strategy

there is no converter current limit, the output current of VSC exceeds its constraint because of extra reactive power injection. By reducing the active power reference properly, the output current is restricted in each phase and the capability of delivering active power is deteriorated with $k_{q}$ moving from 1 towards 0 .

For the same inductive and resistive scenarios described above, the voltage unbalanced factor is plotted in Fig. 7 for flexible/semi-flexible positive- and negative-sequence power control with different combinations of flexible coefficients and 1.2 p.u. converter current limit. It can be observed from Fig. 7(a) that, with fixed $k_{q}$, the voltage unbalanced factor remains almost the same when $k_{p}$ changes. In contrast, the voltage unbalanced factor decreases by fixing $k_{p}$ and reducing $k_{q}$. This confirms that the injection of negative-sequence active power doesn't affect grid voltage so much for inductive scenario while negative-sequence reactive power injection helps mitigate voltage unbalance. In Fig. 7(b), the voltage unbalance factor increases when $k_{p}$ tends from 1 towards 0 with the same value of $k_{q}$, which verifies that negative-sequence active power injection tends to deteriorate voltage balance for resistive grids. In addition, when $k_{p}$ is fixed, a decrease in $k_{q}$ mitigates voltage unbalance as the inductive scenario does, but the impact from $k_{p}$ is more than that from $k_{q}$. This is because of the nonpurely-resistive grid and the existence of interface transformer, which introduce a certain amount of inductance.

As can be observed in Fig. 7(a) and (b) respectively, semiflexible positive- and negative-sequence power control tends

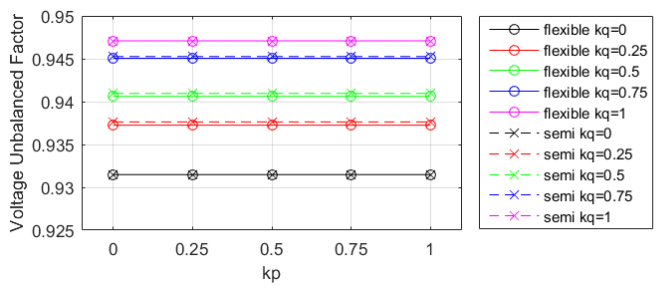

(a) Scenario I: inductive grid

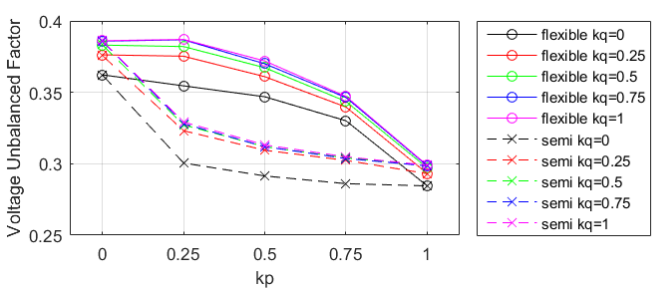

(b) Scenario II: resistive grid

Fig. 7: Voltage unbalanced factor for flexible/semi-flexible positive- and negative-power control

to increase the voltage unbalanced factor for the inductive scenario and reduce it for the resistive scenario compared to flexible positive- and negative-sequence power control with the same values of flexible coefficients. For the inductive scenario, $Q^{+} / Q^{-}$plays a major role in voltage support and an increase in $Q^{+} / Q^{-}$will deteriorate voltage balance. On the contrary, voltage is mainly supported by $P^{+} / P^{-}$in resistive scenario, 
an increase of which helps improve the voltage balance. In Fig. 7(a), $\left|\mathbf{v}^{+}\right|$and $\left|\mathbf{v}^{-}\right|$are close so that the difference between semi-flexible and flexible control is not that apparent. However, with $\left|\mathbf{v}^{+}\right|$more than twice of $\left|\mathbf{v}^{-}\right|$in Fig. 7(b), more differences on voltage unbalanced factor can be observed for these two control strategies.

In general, the short circuit behaviour of VSC under grid unbalanced faults differs from each other significantly with various control strategies, which enable diverse power characteristics of converters and support grid voltage in different ways. The selection of control strategies can be actually regarded as the selection of flexible coefficients and special care should be taken when calculating current references to avoid infinity. In addition, the feasibility of including grid impedance information as control parameters requires further investigation considering the dynamics of the systems. Ability to inject active and reactive power simultaneously complying with the converter current limit is gaining attention, and the power references should be obtained fast and accurately.

\section{CONCLUSION}

This paper reviews grid-connected VSC control for short circuit power provision under grid unbalanced faults in terms of two groups, power-characteristic-oriented control strategy and voltage-support-oriented control strategy. Taking semiconductor capabilities into account, converter current limit issue is also reviewed. With different control strategies under unbalanced faults, the fault current and short circuit power provided by converters can exhibit diverse characteristics and thus the grid voltage is supported in various ways. Since there is no specific requirement regarding unbalanced faults for grid-connected converters at this moment, each control strategy should be further studied exclusively to help define the next generation of grid codes, which take the control over negative-sequence current into consideration. As the short circuit power provided by VSC with different control strategies varies significantly under unbalanced faults, these strategies should also be evaluated based on the performance of protective relays in order to benefit power system operation to the maximum extent.

\section{REFERENCES}

[1] "Energy and climate change," International Energy Agency, Paris, France, 2015.

[2] "Energy strategy 2050-from coal, oil and gas to green energy," The Danish Ministry of Climate and Energy, Copenhagen, Denmark, Feb. 2011.

[3] (2016, Sep.) The massive integration of power electronic devices. [Online]. Available: https://www.h2020-migrate.eu

[4] (2016, Sep.) Prosmart, kpn-project energix. [Online]. Available: http://www.ntnu.edu/prosmart

[5] (2016, Sep.) Application of synchronous condensers. [Online]. Available: http://www.scapp.dk

[6] Measurement and assessment of power quality characteristics of grid connected wind turbines, IEC Std. 61400-21:2008, Aug. 2008.

[7] S. M. Holder, L. Hang, and B. K. Johnson, "Investigation of transmission line protection performance in an electric grid with electronically coupled generation," in Proc. North Amer. Power Symp., Manhatan, KS, USA, Sep. 22-24, 2013.

[8] A. Roy and B. K. Johnson, "Transmission side protection performance with Type-IV wind turbine system integration," in Proc. North Amer. Power Symp., Pullman, Washington, USA, Sep. 7-9, 2014.
[9] L. He, C. Liu, A. Pitto, and D. Cirio, "Distance protection of AC grid with HVDC-connected offshore wind generators," IEEE Trans. Power Del., vol. 29, no. 2, pp. 493-501, Apr. 2014.

[10] R. Li, C. Booth, A. Dyśko, A. Roscoe, H. Urdal, and J. Zhu, "Protection challenges in future converter dominated power systems: demonstration through simulation and hardware tests," in Proc. Int. Conf. Renewable Power Gener, Beijing, China, Oct. 17-18, 2015.

[11] M. P. Kazmierkowski and L. Malesani, "Current control techniques for three-phase voltage-source PWM converters: a survey," IEEE Trans. Ind. Electron., vol. 45, no. 5, pp. 691-703, Oct. 1998.

[12] A. Timbus, M. Liserre, R. Teodorescu, P. Rodriguez, and F. Blaabjerg, "Evaluation of current controllers for distributed power generation systems," IEEE Trans. Power Electron., vol. 24, no. 3, pp. 654-664, Mar. 2009.

[13] F. Blaabjerg, R. Teodorescu, M. Liserre, and A. V. Timbus, "Overview of control and grid synchronization for distributed power generation systems," IEEE Trans. Ind. Electron., vol. 53, no. 5, pp. 1398-1409, Oct. 2006.

[14] H. D. Tafti, A. I. Maswood, Z. Lim, G. H. P. Ooi, and P. H. Raj, "A review of active/reactive power control strategies for PV power plants under unbalanced grid faults," in Proc. IEEE Innovative Smart Grid Technologies-Asia, Bangkok, Thailand, Nov. 3-6, 2015.

[15] Q. Zhong and G. Weiss, "Synchronverters: inverters that mimic synchronous generators," IEEE Trans. Ind. Electron., vol. 58, no. 4, pp. 1259-1267, Apr. 2011.

[16] R. Aouini, B. Marinescu, K. B. Kilani, and M. Elleuch, "Synchronverterbased emulation and control of hvdc transmission," IEEE Trans. Power Systems, vol. 31, no. 1, pp. 278-286, Jan. 2016.

[17] Q. Zhong, Z. Ma, W. Ming, and G. C. Konstantopoulos, "Grid-friendly wind power systems based on the synchronverter technology," Elsevier Energy Conversion and Management, vol. 89, pp. 719 - 726, Jan. 2015.

[18] Network code on requirements for grid connection applicable to all generators, ENTSO-E, Brussels, Belgium, Apr. 2016.

[19] J. Fortmann, R. Pfeiffer, E. Haesen, F. V. Hulle, F. Martin, H. Urdal, and S. Wachtel, "Fault-ride-through requirements for wind power plants in the entso-e network code on requirements for generators," IET Renewable Power Gener, vol. 9, no. 1, pp. 18-24, Jan. 2015.

[20] F. Iov, A. D. Hansen, P. Sørensen, and N. A. Cutululis, "Mapping of grid faults and grid codes," Riso Nat. Lab., Roskilde, Denmark, Tech. Rep., Jul. 2007.

[21] A. D. Hansen, N. A. Cutululis, H. Markou, P. Sørensen, and F. Iov, "Grid fault and design-basis for wind turbines-final report," Riso Nat. Lab., Roskilde, Denmark, Tech. Rep., Jan. 2010.

[22] M. Mohseni and S. M. Islam, "Review of international grid codes for wind power integration: diversity, technology and a case for global standard," Elsevier Renewable and Sustainable Energy Reviews, vol. 16, no. 6, pp. 3876-3890, Apr. 2012.

[23] Ö. Göksu, R. Teodorescu, C. L. Bak, F. Iov, and P. C. Kjaer, "Impact of wind power plant reactive current injection during asymmetrical grid faults," IET Renewable Power Gener, vol. 7, no. 5, pp. 484-492, Sep. 2013.

[24] M. Curzi, R. Sharma, and F. Martin, "In fault ride through reactive current rise time requirements of various European grid codes-analysis based on a full-converter wind turbine," Wind Energy, vol. 19, no. 6, pp. 1121-1133, Jun. 2016.

[25] B. Weise, "Impact of k-factor and active current reduction during faultride-through of generating unit connected via voltage-sourced converters on power system stability," IET Renewable Power Gener., vol. 9, no. 1, pp. 25 - 36, Jan. 2015.

[26] ENTSO-E draft network code on high voltage direct current connections and DC connected power park modules, ENTSO-E, Brussels, Belgium, Apr. 2014.

[27] H. Akagi, E. H. Watanabe, and M. Aredes, Instantaneous power theory and applications to power conditioning. Hoboken, NJ, USA: John Wiley \& Sons, Inc., 2006.

[28] A. Yazdani and R. Iravani, Voltage-sourced converters in power systems: modeling, control, and applications. Hoboken, NJ, USA: John Wiley \& Sons, Inc., 2010.

[29] R. Teodorescu, M. Liserre, and P. Rodrguez, Grid converters for photovoltaic and wind power systems. Chichester, UK: John Wiley \& Sons, Ltd., 2011.

[30] A. Yazdani and R. Iravani, "A unified dynamic model and control for the voltage-sourced converter under unbalanced grid conditions," IEEE Trans. Power Del., vol. 21, no. 3, pp. 1620-1629, Jul. 2006.

[31] P. Xiao, K. A. Corzine, and G. K. Venayagamoorthy, "Multiple reference frame-based control of three-phase PWM boost rectifiers under unbal- 
anced and distorted input conditions," IEEE Trans. Power Electron., vol. 23, no. 4, pp. 2006-2017, Jul. 2008

[32] Y. Liu, N. Li, Y. Fu, J. Wang, and Y. Ji, "Stationary-frame-based generalized control diagram for PWM AC-DC front-end converters with unbalanced grid voltage in renewable energy systems," in Proc. IEEE Appl. Power Electron. Conf. and Expo., Charlotte, NC, USA, Mar. 1519, 2015, pp. 678-683.

[33] K. Ma, W. Chen, M. Liserre, and F. Blaabjerg, "Power controllability of a three-phase converter with an unbalanced ac source," IEEE Trans. on Power Electron., vol. 30, no. 3, pp. 1591-1604, Mar. 2015.

[34] N. B. Lai and K. Kim, "An improved current control strategy for a grid-connected inverter under distorted grid conditions," Energies, vol. 9, no. 3, Mar. 2016

[35] P. Rodriguez, A. V. Timbus, R. Teodorescu, M. Liserre, and F. Blaabjerg, "Flexible active power control of distributed power generation systems during grid faults," IEEE Trans. Ind. Electron., vol. 54, no. 5, pp. $2583-$ 2592, Oct. 2007.

[36] S. Alepuz, S. Busquets-Monge, J. Bordonau, J. A. Martnez-Velasco, C. A. Silva, J. Pontt, and J. Rodrguez, "Control strategies based on symmetrical components for grid-connected converters under voltage dips," IEEE Trans. Ind. Electron., vol. 56, no. 6, pp. 2162-2173, Jun. 2009.

[37] C. H. Ng, L. Ran, and J. Bumby, "Unbalanced-grid-fault ride-through control for a wind turbine inverter," IEEE Trans. Ind. Appl., vol. 44, no. 3, pp. 845-856, May/Jun. 2008.

[38] Z. R. Ivanović, E. M. Adžić, M. S. Vekić, S. U. Grabić, N. L. Čelanović, and V. A. Katić, "HIL evaluation of power flow control strategies for energy storage connected to smart grid under unbalanced conditions,' IEEE Trans. Power Electron., vol. 27, no. 11, pp. 4699-4710, Nov. 2012

[39] H. Song and K. Nam, "Dual current control scheme for PWM converter under unbalanced input voltage conditions," IEEE Trans. Ind. Electron., vol. 45 , no. 5 , pp. $722-729$, Oct. 1998 .

[40] A. Junyent-Ferré, O. Gomis-Bellmunt, T. C. Green, and D. E. SotoSanchez, "Current control reference calculation issues for the operation of renewable source grid interface VSCs under unbalanced voltage sags," IEEE Trans. Power Electron., vol. 26, no. 12, pp. 3744-3753, Dec. 2011.

[41] P. RodrÍguez, A. Timbus, R. Teodorescu, M. Liserre, and F. Blaabjerg, "Reactive power control for improving wind turbine system behavior under grid faults," IEEE Trans. Power Electron., vol. 24, no. 7, pp. 1798-1801, Jul. 2009.

[42] P. Rodriguez, G. Medeiros, A. Luna, M. C. Cavalcanti, and R. Teodorescu, "Safe current injection strategies for a STATCOM under asymmetrical grid faults," in Proc. IEEE Energy Conversion Congr. and Expo., Atlanta, GA, USA, Sep. 12-16, 2010, pp. 3929-3935.

[43] R. Kabiri, D. G. Holmes, and B. P. McGrath, "Control of active and reactive power ripple to mitigate unbalanced grid voltages," IEEE Trans. Ind. Appl., vol. 52, no. 2, pp. 1660-1668, Mar./Apr. 2016.

[44] F. Wang, J. L. Duarte, and M. A. M. Hendrix, "Design and analysis of active power control strategies for distributed generation inverters under unbalanced grid faults," IET Gener. Transm. Distrib., vol. 4, no. 8, pp. 905-916, Aug. 2010.

[45] F. Wang, J. L. Duarte, and M. Hendrix, "Pliant active and reactive power control for grid-interactive converters under unbalanced voltage dips," IEEE Trans. Power Electron., vol. 26, no. 5, pp. 1511-1521, May 2011.

[46] P. Rodríguez, A. V. Timbus, R. Teodorescu, M. Liserre, and F. Blaabjerg, "Independent PQ control for distributed power generation systems under grid faults," in Proc. IEEE Annu. Conf. Ind. Electron., Paris, France, Nov. 6-10, 2006, pp. 5185-5190.

[47] J. Miret, A. Camacho, M. Castilla, L. G. D. Vicuña, and J. Matas, "Control scheme with voltage support capability for distributed generation inverters under voltage sags," IEEE Trans. Power Electron., vol. 28 no. 11 , pp. 5252-5262, Nov. 2013

[48] M. Castilla, J. Miret, A. Camacho, J. Matas, and L. G. D. Vicuña, "Voltage support control strategies for static synchronous compensators under unbalanced voltage sags," IEEE Trans. Ind. Electron., vol. 61, no. 2, pp. 808-820, Feb. 2014.

[49] A. Camacho, M. Castilla, J. Miret, R. Guzman, and A. Borrell, "Reactive power control for distributed generation power plants to comply with voltage limits during grid faults," IEEE Trans. Power Electron., vol. 29, no. 11, pp. 6224-6234, Nov. 2014.

[50] F. Nejabatkhah, Y. Li, and B. Wu, "Control strategies of three-Phase distributed generation inverters for grid unbalanced," IEEE Trans. Power Electron., vol. 31, no. 7, pp. 5228-5241, Jul. 2016.

[51] X. Guo, X. Zhang, B. Wang, W. Wu, and J. M. Guerrero, "Asymmetrical grid fault ride-through strategy of three-phase grid-connected inverter considering network impedance impact in low-voltage grid," IEEE Trans. Power Electron., vol. 29, no. 3, pp. 1064-1068, Mar. 2014.
[52] M. Castilla, J. Miret, A. Camacho, J. Matas, E. Alarcón-Gallo, and L. G. D. Vicuña, "Coordinated reactive power control for static synchronous compensators under unbalanced voltage sags," in IEEE Int. Symp. on Ind. Electron., Hangzhou, China, May 28-31, 2012, pp. $987-$ 992.

[53] A. Camacho, M. Castilla, J. Miret, J. C. Vasquez, and E. Alarcón-Gallo, "Flexible voltage support control for three-phase distributed generation inverters under grid fault," IEEE Trans. Ind. Electron., vol. 60, no. 4, pp. 1429-1441, Apr. 2013.

[54] P. Rodriguez, A. Luna, J. R. Hermoso, I. Etxeberria-Otadui, R. Teodorescu, and F. Blaabjerg, "Current control method for distributed generation power generation plants under grid fault conditions," in Proc. IEEE Аnnu. Conf. Ind. Electron., Melbourne, Australia, Nov. 7-10, 2011, pp. 1262-1269.

[55] A. Camacho, M. Castilla, J. Miret, A. Borrell, and L. G. D. Vicuña, "Active and reactive power strategies with peak current limitation for distributed generation inverters during unbalanced grid faults," IEEE Trans. Ind. Electron., vol. 62, no. 3, pp. 1515-1525, Mar. 2015.

[56] M. A. Fotouhi, Z. Vale, R. Castro, S. F. Pinto, and F. A. Silva, "Flexible operation of grid-interactive converters under unbalanced grid conditions," Advanced Sci. and Tech. Lett., vol. 97, pp. 1-9, 2015.

[57] X. Guo, W. Liu, X. Zhang, X. Sun, Z. Lu, and J. M. Guerrero, "Flexible control strategy for grid-connected inverter under unbalanced grid faults without PLL," IEEE Trans. Power Electron., vol. 30, no. 4, pp. 17731778, Jul. 2014

[58] S. Revelo and C. A. Silva, "Current reference strategy with explicit negative sequence component for voltage equalization contribution during asymmetric fault ride through," Int. Trans. Elect. Energ. Syst., vol. 25, no. 12 , pp. $3449-3471$, Dec. 2015.

[59] O. Ojo and Z. Wu, "A new controller for three-phase boost rectifiers lacking balance in source votages and impedances," in Proc. IEEE Appl. Power Electron. Conf. and Expo., Austin, Texas, USA, Mar. 6-10, 2005, pp. 508-514.

[60] C. Lee, C. Hsu, and P. Cheng, "A low-voltage ride-through technique for grid-connected converters of distributed energy resources," IEEE Trans. Ind. Appl., vol. 47, no. 4, pp. 1821-1832, Jul./Aug. 2011.

[61] J. Miret, M. Castilla, A. Camacho, L. G. D. Vicua, and J. Matas, "Control scheme for photovoltaic three-phase inverters to minimize peak currents during unbalanced grid-voltage sags," IEEE Trans. Power Electron., vol. 27 , no. 10 , pp. $4262-4271$, Oct. 2012.

[62] Z. Ivanović, M. Vekić, S. Grabić, and V. Katić, "Control of multilevel converter driving variable speed wind turbine in case of grid disturbances," in Proc. Int. Power Electron. and Motion Control Conf., Portoroz, Slovenia, Aug. 30-Sep. 1, 2006, pp. 1569-1573.

[63] A. Milicua, G. Abad, and M. Á. R. Vidal, "Online reference limitation method of shunt-connected converters to the grid to avoid exceeding voltage and current limits under unbalanced operation part i: theory," IEEE Trans. Energy Convers., vol. 30, no. 3, pp. 852-863, Sep. 2015.

[64] J. L. Sosa, M. Castilla, J. Miret, J. Matas, and Y. A. Al-Turki, "Control strategy to maximize the power capability of pv three-phase inverters during voltage sags," IEEE Trans. on Power Electron., vol. 31, no. 4, pp. 3314-3323, Apr. 2016.

[65] Technical regulation 3.2.5 for wind power plants with a power output above $11 \mathrm{~kW}$, Energinet, Fredericia, Denmark, Jun. 2015.

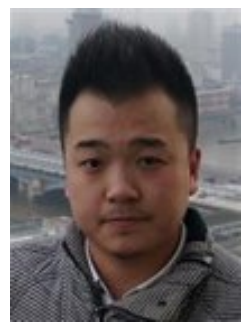

Jundi Jia received the B.Sc. degree in electrical engineering and automation from Beijing Jiaotong University, China, in 2012, and the M.Sc degree in electric power engineering from Royal Institute of Technology, Sweden, in 2014. Afterwards, he was an analyst on resource utilities in Accenture, China. Currently, he is pursuing his Ph.D. degree in the Center for Electric Power and Energy, Department of Electrical Engineering, Technical University of Denmark. His research interests include power system dynamics and protection, control of power-electronic converters and integration of renewable energy. 


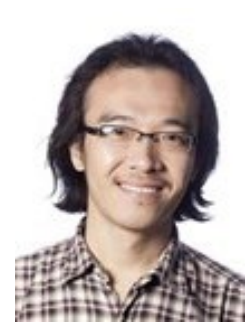

Guangya Yang received the B.E., M.E., and Ph.D. degrees all in the field of electric power system, in 2002, 2005, and 2008, respectively. Since 2009, he has been with the Technical University of Denmark, Kongens Lyngby, Denmrk, as a Postdoctoral Researcher, and he is currently an Associate Professor with the Center for Electric Power and Energy, Department of Electrical Engineering, Technical University of Denmark. Since 2009, he has been leading several industrial collaborative projects in Denmark in the field of monitoring, operation and protection of renewable energy systems. His research interests include renewable energy integration, smart grids, and cyber physical energy systems.

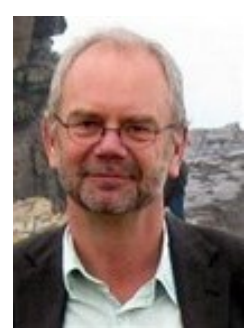

system.
Arne Hejde Nielsen is an Associate Professor at the Centre for Electric Power and Energy, Department of Electrical Engineering, Technical University of Denmark, Konges Lyngby, Denmark. He has 30 years experience in electric power engineering; the first years were from ASEA AB, Central Research and Development Department, Sweden, with focus on measurement technology and motor design and control. Over the past decade his focus has been on electric power systems, especially on implementation of renewable energy sources in the power 